Огляди літератури, оригінальні дослідження, погляд на проблему, випадок з практики, короткі повідомлення

УДК 61(510): [616.9-02: 578.834.1]

DOI 10.11603/1811-2471.2021.v.i3.12502

\title{
ЗАСТОСУВАННЯ МЕТОДІВ ТРАДИЦІЙНОї КИТАЙСЬКОЇ МЕДИЦИНИ В ІНТЕГРАТИВНОМУ ЛІКУВАННІ ТА РЕАБІЛІТАЦІЇ ХВОРИХ НА COVID-19 В ПРАКТИЦІ СІМЕЙНОї МЕДИЦИНИ
}

\author{
๑О. М. Головчанський, О. І. Висоцька, Г. М. Виноградова, В. І. Висоцький,
}

А. В. Сковронська, В. І. Бик, А. А. Бакуліна

Національний медичний університет імені О. О. Богомольця

PEзЮмЕ. Активна реалізація інтегративних підходів до лікування хворих на COVID-19 демонструє високу терапевтичну ефективність. Застосування методів традиційної китайської медицини (ТКМ) разом із конвенціональною медициною дозволило знизити рівень смертності і підвищити рівень і якість одужання.

Мета - вивчити особливості використання методів TКМ (зокрема вплив на точки акупунктури) в інтегративному лікуванні хворих на COVID-19.

Матеріал і методи. Інформаційні бази наукових публікацій, літературні джерела, аналітично-інформаційні матеріали. Використано методи бібліосемантичного дослідження, контент-аналізу, системного підходу.

Результати. Встановлено, що 87 \% пацієнтів з COVID-19 отримували лікування методами TKM (голковколювання і фітотерапію); позитивного результату лікування пацієнтів, які отримували лікування методами ТКМ, досягнуто у $92 \%$.

Висновки. ТКМ має ефективні напрацювання в боротьбі з інфекційними захворюваннями, що варто наукового дослідження і впровадження в клінічну практику на рівні закладів первинної медичної допомоги. Інтеграція конвенціональної та традиційної китайської медицини для профілактики, лікування та реабілітації хворих на COVID-19, реалізована в KHP, показала високу терапевтичну ефективність. Упровадження в практику лікарів загальної практики - сімейної медицини терапевтичних технік ТКМ є перспективним, але потребує системної організаційної роботи, зокрема організації циклів тематичного удосконалення. Актуальноює організація взаємодії лікарів загальної практики-сімейної медицини з лікарями-рефлексотерапевтами для широкого впровадження технічно простих методів ТКМ у реабілітацію постковідних пацієнтів.

КЛючОВІ СлОВА: інтегративна медицина; традиційна китайська медицина; акупунктура; сімейна медицина.

Вступ. На сьогодні специфічної антивірусної терапії COVID-19 не існує, масова вакцинація в Україні тільки починається, довготривала її ефективність невідома. Протягом 2020 року в Україні було затверджено декілька редакцій протоколу надання медичної допомоги хворим на COVID-19, а в січні 2021 - «Клінічне ведення пацієнтів 3 COVID-19 «Жива» клінічна настанова». За основу було взято настанову ВОО3 «Clinical management of COVID-19: interim guidance» (27.05.2020), яка, на думку авторів, більшою мірою відповідає специфіці медичної допомоги в Україні. На жаль, позитивний досвід і рекомендації медицини КНР не були взяті до уваги. Опинившись віч-на-віч з епідемією COVID-19, KHP активно реалізувала інтегративне лікування пацієнтів: разом із конвенціональною медициною застосовували фітотерапію, голковколювання і припікання для профілактики і лікування цього захворювання. Пекінська комісія з охорони здоров'я відмічає, що 87 \% пацієнтів з COVID-19 отримували лікування методами традиційної китайської медицини (ТКМ) (голковколювання і фітотерапію). Позитивний результат лікування пацієнтів, які отримували лікування методами ТКМ, досягнуто у $92 \%$ [1]. ТКМ відіграла активну роль у зниженні рівня смертності й підвищенні рівня одужання.

Мета. Результати лікування і профілактики COVID-19 із застосуванням методів і засобів тради- цийної китайської медицини в КНР спонукають до глибшого дослідження і вивчення можливостей впровадження їх у щоденну практику сімейного лікаря, що й стало метою даного дослідження.

Матеріл і методи дослідження. Зважаючи на актуальність досліджуваного питання автори провели розширений інформаційний пошук у доступних джерелах. Варто зазначити, що більшість публікацій, присвячених висвітленню досвіду лікування і профілактики COVID-19 у KHP, подаються китайською мовою, перекладів чи статей англійською мовою - одиниці. Величезний пласт інформації, таким чином, залишається недоступним для аналізу, опрацювання і поширення. Для бібліосемантичного дослідження методами системного підходу було відібрано три джерела, які відповідали вимогам і підлягали контент-аналізу (див. Список використаних джерел).

Результати й обговорення. Оскільки задачею практики семейної медицини $\epsilon$ раннє виявлення хворих на COVID-19 і вчасна ефективна терапія, що дозволяє зменшити кількість пацієнтів з перебігом середнього і тяжкого ступенів, а також супровід і допомога пацієнтам з постковідним синдромом і лонг-ковід синдромом, то пропонуємо ознайомитись з нормативними документами КНР для лікування пацієнтів з COVID-19. Це «Diagnosis and Treatment Protocol for COVID-19 Patients (Tentative 
Огляди літератури, оригінальні дослідження, погляд на проблему, випадок з практики, короткі повідомлення

8th Edition)" [2] та "Guidelines on Acupuncture and Moxibustion Intervention for COVID-19 (second edition)» [3], які рекомендують Головний офіс Національної комісії з охорони здоров'я КНР та Головний офіс Національної адміністрації традиційної китайської медицини, які було розроблені для медичних працівників для застосування акупунктури у веденні хворих на COVID-19.

Як свідчать Guidelines on Acupuncture and Moxibustion Intervention for COVID-19 (second edition), у категоріях TKM COVID-19 належить до «епідемічних» захворювань. Упродовж тисячоліть ТКМ набула багатого досвіду в боротьбі з епідеміями, застосовуючи для цього голковколювання і припікання. Наприклад, Сун Симяо, лікар епохи династії Тань (VII-X ст.), у своїй книзі Веіjі Qiangjin Yao Fang («Золоті рецепти для кожної надзвичайної ситуації) пише: «Тим, хто подорожує в райони розповсюдження інфекційних захворювань, часто потрібне припалювання з утворенням кірок, щоб вони не були заражені малярією та малярійною гарячкою». В трактаті Ben cao gang mu («Компедіум лікарських речовин») Лі Ші Чжен, лікар епохи династії Мінь (XIV-XVII ст.), відмічає, що «припікання полинними цигарками може сприяти прохідності енергії по меридіанах, лікувати сотні захворювань і оздоровлювати людей, які хворіють упродовж тривалого часу». В обох цих книгах $\epsilon$ вказівки на ефективність ТКМ у лікуванні інфекційних захворювань.

Сучасні клінічні та експериментальні дослідження доводять, що голковколювання і припікання регулюють функцію імунної системи, мають протизапальну та антиінфекційну дію. Оскільки лікарі загальної практики-сімейної медицини відповідно до кваліфікаційних вимог мають володіти немедикаментозними методами підтримання здоров'я і лікування, то вони цілком можуть використовувати такі технічно прості техніки лікування, як масаж точок акупунктури та їх прогрівання полинними цигарками або аплікаціями 3 зігріваючим ефектом (наприклад, перцепластир).

І. Принципи застосування голковколювання

1. Упродовж епідемії втручання на точки акупунктури має підпорядковуватися загальній ситуації та проводитися методично під керівництвом медичних установ усіх рівнів. Лікар повинен проводити втручання відповідно до вимог карантину і дезінфекції. При лікуванні пацієнтів із штучною вентиляцією легень (кисневою підтримувальною терапією) процедури повинні виконуватися з дотриманням правил безпеки.

2. Клінічний діагноз, стадійність, класифікація, синдромальне диференціювання TKM для COVID-19, а також план лікування, повинні відповідати «Diagnosis and Treatment Protocol for
COVID-19 Patients (Tentative 8th Edition)». Водночас слід повністю враховувати особливості голкорефлексотерапії, щоб зробити втручання на точки більш відповідним. Інфекція потрапляє до організму людини через рот і ніс, і у більшості пацієнтів найперше вражає легені, потім селезінку, шлунок та товсту кишку, і перебіг захворювання відносно легкий; незначна частина потрапляє до перикарда, печінки і нирок, тоді стан стає критично тяжким. Захворювання швидко змінюється та має чіткий стрижень патогенезу і еволюцію синдромів. Голковколюванням стимулюють акупунктурні точки меридіанів внутрішніх органів на кінцівках та на зовнішніх колатеральних відгалуженнях, таким чином в організмі людини створюються несприятливі для життя вірусу умови. Одночасно стимуляція точок акупунктури також покращує самозахист внутрішніх органів і зменшує їх ушкодження, спричинене інфекцією.

3. Лікування акупунктурою, відповідно до патогенетичного розвитку, можна поділити на три фази - фаза медичного спостереження, фаза клінічного лікування і фаза реконвалесценції. Відповідно до розпізнаних синдромів ураження органів і меридіанів, лікування проводиться на основних акупунктурних точках і на додаткових точках відповідно до клінічних симптомів. Лікар має обирати належні процедури голковколювання чи припікання відповідно до особливих обставин, дотримуючись принципу «зручно, просто, безпечно та ефективно». Акупунктуру можна застосовувати синергічно разом із фітотерапією. У терапії пацієнтів, які одужують, акупунктура має відігравати провідну роль.

4. Вибір точок і методів впливу на них спирається на доказові дані давньої літератури, сучасні клінічні та теоретичні дослідження, а також включає результати проведених раніше спостережень з оцінки впливу акупунктури для покращення функції легень, регуляції імунітету, протизапальних факторів, активації ваго-холінергічної протизапальної дії, регуляції дихальної системи і відновлення пошкодження після запалення легень.

5. Пацієнтів слід заохочувати проводити припікання та інші техніки впливу на точки - аплікації, масаж тощо, під керівництвом професійних акупунктуристів, використовуючи різноманітні комунікатори - інтернет, мобільні телефони з відповідними додатками, для допоміжного лікування захворювання і для сприяння фізичній і розумовій реабілітації. Особливу увагу слід приділяти спілкуванню лікаря і пацієнта, спостереженню (диспансеризації), а також вчасному і повному збору інформації щодо діагностики і лікування для узагальнення і аналізу. 
Огляди літератури, оригінальні дослідження, погляд на проблему, випадок з практики, короткі повідомлення

II. Методи втручання при голковколюванні і припіканні

1. У фазі медичного спостереження (підозра на COVID-19).

Мета: стимулювати життєву ЧІ (енергію) та функції легень і підшлункової залози та розсіювати, відокремлювати і видаляти патогени - збудники захворювання, покращувати захист внутрішніх органів у боротьбі з патогенами.

Основні точки: 1) Fengmen (BLl2), Feishu (BLl3), Pishu (BL20); 2) Hegu (LI4), Quchi (LI11), Chize (LU5), Yuji (LU10); 3) Qihai (CV6), Zusanli (ST36), Sanyinjiao (SP6). Для кожного сеансу обирайте 1-2 точки у кожній з трьох вказаних груп.

Додаткові точки:

$\checkmark$ за наявності симптомів, пов'язаних із підвищеною температурою, сухістю в горлі, сухим кашлем, показані точки Dazhui (GVl4), Tiantu (CV22), Kongzui (LU6);

$\checkmark$ за наявності нудоти, блювання, проносу, жирного сірого нальоту на язику, м'якого (слизького) пульсу потрібно впливати дією на точки Zhongwan (CVI2), Tianshu (ST25), Fenglong (ST40);

$\checkmark$ за наявності утоми, слабкості, відсутності апетиту показана дія на точки Zhongwan (CVl2), чотири точки навколо пупка (по 1 дюйму) від пупка по всіх чотирьох напрямках), Pishu (BL20);

$\checkmark$ за наявності виділень з носа, болісних відчуттів у плечах і спині, блідого язика з білим нальотом, повільного пульсу, показаний вплив на точки Tianzhu (BLl0), Fengmen (BLl2), Dazhui (GVl4).

2. Голковколювання та припікання упродовж одужання.

Мета: усунути залишковий патоген, відновити життєву силу пацієнта, налагодити функції внутрішніх органів (на першому місці - легень і підшлункової залози).

Основні точки: Neiguan (PC6), Zusanli (ST36), Zhongwan (CVl2), Tianshu (ST25), Qihai (CV6).

1. Синдром недостатності ЧІ легень і підшлункової залози: задишка, втомлюваність, відсутність апетиту, блювання, роздутий шлунок, відчуття слабкості під час дефекації, послаблення випорожнень, язик дещо збільшений, із білим жирним нальотом. Для тих, хто має явні симптоми - стягнутість у грудях, задишку, показаний вплив на точки Danzhong (CVl7), Feishu (BLl3), Zhongfu (LU1). Для тих, хто має явні ознаки ураження підшлункової залози і шлунка, наприклад, нетравлення та пронос, застосовують точки Shangwan (CVI3), Yinlingquan (SP9).

2. Синдром недостатності ЧІ та ІНь: слабкість, сухість у роті, спрага, серцебиття, надмірне потовиділення, знижений апетит, невелика гарячка або її відсутність, сухий кашель з незначною кількістю мокротиння, сухий язик з недостатнім сли- новиділенням, пульс тонкий або слабкий. Для пацієнтів з явними ознаками слабкості та задишки показаний вплив на точки Danzhong (CVl7), Shenque (CV8). Для тих, у кого виражена сухість ротової порожнини та спрага, показаний вплив на точки Taixi (KI3), Yangchi (TE4). Тим, у кого є серцебиття, впливають на точки Xinshu (BLI5), Jueyinshu (BL14). Пацієнтам з надмірним потовиділенням застосовують точки Hegu (LI4), Fuliu (KI7), Zusanli (ST36). Тим, хто скаржиться на безсоння, діють на точки Shenmen (HT7), Yintang (GV29), Anmian (EX), Yongquan (KI1).

3. Синдром недостатності легень і підшлункової залози та селезінки, застій слизу, що блокує плин енергії по меридіанах: відчуття стягнутості у грудях, задишка, небажання спілкуватися (говорити), втомлюваність, потовиділення при русі, кашель з виділенням мокротиння, застій слизу, луската суха шкіра, розумова втома, відсутність апетиту тощо потребують впливу на точки Feishu (BLl3), Pishu (BL20), Xinshu (BLI5), Geshu (BL17), Shenshu (BL23), Zhongfu (LU1), Danzhong (CVl7). Тим, у кого виявляється застій слизу, показаний вплив на точки Fenglong (ST40) та Dingchuan (EXB1).

Маніпуляції при голковколюванні та припіканні: обираються ті, які належним чином відповідають умовам обстановки, в якій буде проводитися втручання, та організаційним вимогам.

При лікуванні пацієнтів, перебіг захворювання яких відповідає вказаним фазам, рекомендовано обирати або тільки голковколювання, або тільки припікання, або комбінацію обох методів, або поєднувати з аплікаційним впливом на акупунктурні точки, аурикуло-акупунктурою, фармакопунктурою, шкребковим масажем (гуаша), педіатричним масажем, акупресурою тощо, відповідно до ситуації. При голковколюванні варто використовувати помірні методи стимуляції або розсіювання. Голки потрібно залишати на кожній точці на 20-30 хвилин; припікання кожної точки має продовжуватися 10-15 хвилин. Лікування потрібно проводити один раз на день.

3. Голковколювання та припікання під контролем лікаря в домашніх умовах.

Для покращення запобігання та контролю епідемії COVID-19, зменшення кількості контактів, виключення перехресної інфекції, блокування джерел інфікування, а також для забезпечення безпеки, пацієнти, які знаходяться на карантині/самоізоляції, які виписані з лікарень, можуть проводити втручання голковколювання і припікання через онлайн клініки, онлайн супровід, наукову популяризацію та навчання, під керівництвом професіоналів.

Припікання: самоприпікання точок Zusanli (ST36), Neiguan (PC6), Hegu (LI4), Qihai (CV6), 
Огляди літератури, оригінальні дослідження, погляд на проблему, випадок з практики, короткі повідомлення

Guanyuan (CV4), Sanyinjiao (SP6). Кожна процедура припікання займає близько 10 хвилин.

Аплікації: зігріваюча полинова паста чи крем наносяться на точки Zusanli (ST36), Neiguan (PC6), Qihai (CV6), Guanyuan (CV4), Feishu (BLI3), Fengmen (BLl2), Pishu (BL20), Dazhui (GVl4).

Масаж меридіанів: розминання, натискання, розтирання, постукування, погладжування на меридіанах легень і серця на верхніх кінцівках, а на меридіанах підшлункової залози - селезінки нижче колін. Тривалість 15-20 хвилин для кожної маніпуляції. Відчуття болю в ділянці, що обробляється, $€$ закономірним і допустимим явищем, оскільки свідчить про наявність перешкод вільному руху енергії в цьому меридіані.

Традиційні вправи: обирайте відповідну традиційну гімнастику, як Yi Jin Jing («Зміни сухожиль»), Tai Chi, Ba Duan Jin («8 шматків парчі»), Wu Qin Xi («Рухи 5 тварин»), тощо, які базуються на індивідуальній ситуації в фазі одужання. Виконувати вправи варто один раз на день, по 15-30 хвилин.

Ментальне здоров'я: робота з емоціями. Для цього можна використовувати аурикулярні точки, припікання, масаж, лікувальну дієту, трав'яні чаї, трав'яні ванни, музику та інші способи розслаблення, як фізичного, так і ментального, щоб зменшити тривожність і нормалізувати сон.

Висновки. 1. Традиційна китайська медицина має ефективні напрацювання в боротьбі з інфекційними захворюваннями. Вони варті наукового дослідження і впровадження в клінічну практику на рівні закладів первинної медичної допомоги.

2. Інтеграція конвенціональної та традиційної китайської медицини для профілактики, лікування та реабілітації хворих на COVID-19, реалізована в КНР, показала високу терапевтичну ефективність.

3. Впровадження в практику лікарів загальної практики - сімейної медицини терапевтичних технік традиційної китайської медицини $\epsilon$ перспективним, але потребує системної організаційної роботи, зокрема організації циклів тематичного удосконалення.

4. На сьогодні актуальною $є$ організація взаємодії лікарів загальної практики - сімейної медицини з лікарями-рефлексотерапевтами для широкого впровадження технічно простих методів традиційної китайської медицини в реабілітацію постковідних пацієнтів.

\section{ЛІТЕРАТУРА}

1. [site of Xinhua]. Beijing: The total effective rate of Chinese medicine treatment for new coronary pneumonia is $92 \%$. Retrieved from: http:///www.xinhuanet.com/ politics/2020-02/24/c_1125620808.htm

2. Diagnosis and Treatment Protocol for COVID-19 Patients (Tentative 8th Edition). Updated: 2020-09-07. Guest Editor (s): Haijuan Wang, (Released by National Health Commission \& National Administration of
Traditional Chinese Medicine on August 18, 2020) Retrieved from: https://www.ncbi.nlm.nih.gov/pmc/ articles/PMC8057316/

3. Guidelines on Acupuncture and Moxibustion Intervention for COVID-19 (second edition). Retrieved from: http://http://en.wfas.org.cn/news/detail.html?nid=5403\& cid=25 http://39.96.5.68:8080/uploads/20200303/ 202003032241238046.pdf

\section{REFERENCES}

1. [site of Xinhua]. Beijing: The total effective rate of Chinese medicine treatment for new coronary pneumonia is $92 \%$. Retrieved from: http:///www.xinhuanet.com/ politics/2020-02/24/c_1125620808.htm

2. Diagnosis and Treatment Protocol for COVID-19 Patients (Tentative 8th Edition). Updated: 2020-09-07. Guest Editor (s): Haijuan Wang, (Released by National Health Commission \& National Administration of Traditional

Chinese Medicine on August 18, 2020) Retrieved from: https://www.ncbi.nlm.nih.gov/pmc/articles/PMC8057316/

3. Guidelines on Acupuncture and Moxibustion Intervention for COVID-19 (second edition). Retrieved from: http://http://en.wfas.org.cn/news/detail.html?nid=5403\& cid=25 http://39.96.5.68:8080/uploads/20200303/ 202003032241238046.pdf 
Огляди літератури, оригінальні дослідження, погляд на проблему, випадок з практики, короткі повідомлення

\section{APPLICATION OF TRADITIONAL CHINESE MEDICINE METHODS IN THE INTEGRATIVE TREATMENT AND REHABILITATION OF PATIENTS WITH COVID-19 IN THE PRACTICE OF FAMILY MEDICINE}

\section{O. M. Golovchanskyi, O. I. Vysotska, G. M. Vynogradova, V. I. Vysotskyi,} A. V. Skovronska, V. I. Byk, A. A. Bakulina

\section{O. O. Bohomolets National Medical University}

SUMMARY. The active implementation of integrative approaches to the treatment of COVID-19 patients demonstrates high therapeutic efficacy. The use of traditional Chinese medicine (TCM) methods together with conventional medicine has reduced the mortality rate and increased the level and quality of recovery.

The aim - to study the features of the use of TCM methods (in particular, the effect on acupuncture points) in the integrative treatment of patients with COVID-19.

Material and Methods. Information bases of scientific publications, literary sources, analytical and information materials. The methods of bibliosemantic research, content analysis, and a systematic approach were used.

Results. It was found that $87 \%$ of patients with COVID-19 received treatment with TCM (acupuncture and herbal medicine), a positive result of treatment of patients treated with TCM was achieved in $92 \%$.

Conclusions. TCM has effective experience in the fight against infectious diseases and deserves scientific research and implementation in clinical practice at the level of primary health care institutions. The integration of conventional and traditional Chinese medicine for the prevention, treatment and rehabilitation of patients with COVID-19, implemented in the PRC, has shown high therapeutic efficiency. The introduction of therapeutic techniques of TCM into the practice of general practitioners, family medicine, is promising, but requires systemic organizational work, in particular, the organization of cycles of thematic improvement. The organization of interaction between general practitioners and reflexotherapists for the widespread introduction of technically simple TCM methods in the rehabilitation of post-COVID patients is relevant.

KEY WORDS: integrative medicine; traditional Chinese medicine; acupuncture; family medicine.

Отримано 12.09.2021 